\title{
Adrift in the System
}

\author{
Danielle Massarella
}

I had the opportunity to see a 17-year-old male who had been referred to the pediatric cardiology clinic after his foster care intake exam resulted with an abnormal EKG. He came to the appointment with a group home staff member who knew none of his past medical history, allergies, or current prescribed medications. He was new to our health system and his electronic medical records were outdated and sparse. The answer to every question I asked this young man to ascertain his cardiovascular risk was "I don't know." He had no family history to share and none of his birth history or even surgical history was known to him.

He was ultimately diagnosed with hypertrophic cardiomyopathy. He was advised against continuing his favorite pastimes, which included basketball and weight training. I had the strong sense that we were lowering the weight of the world onto the shoulders of this young man. Understanding the implications of a diagnosis like this is beyond most 17-year-olds I know; and I felt helpless in the situation as I looked at his "caregiver" across the room, texting disinterestedly on his phone while the attending physician was talking to the patient about our findings. I have not seen the boy since. He was lost to follow-up immediately after this visit. With such a serious condition and scarcely anyone around to care for him, I worry that few things will ever go his way. It just feels like the end of my clinic visit should not be the end of the story or the end of us caring for this young man.

D. Massarella $(\bowtie)$

MetroHealth Medical Center, Cleveland, OH, USA 